\title{
Transmissão de fungo entomopatogênico no controle da broca do rizoma
}

\section{Transmission of entomopathogenic fungi on banana weevil control}

\author{
Ernesto Antonio Lema López ${ }^{1 *}$; Pedro Manoel Oliveira Janeiro Neves²; \\ Marilene Fancelli ${ }^{3}$
}

\begin{abstract}
Resumo
O objetivo deste trabalho foi avaliar a transmissão do fungo entomopatogênico (Beauveria bassiana) entre adultos da broca do rizoma (Cosmopolites sordidus) em condições de campo. Insetos adultos e sadios de $C$. sordidus foram marcados e liberados na base de touceiras de bananeiras e dois dias após na mesma área foram liberados insetos marcados e inoculados com o fungo B. bassiana. Aos 7, 14, 21 e 28 dias armadilhas de pseudocaule foram utilizadas para a recaptura dos insetos e determinação da mortalidade pelo fungo. Observou-se uma porcentagem de infecção de $3,7 \%$ dos insetos sadios recuperados, caracterizando a transmissão de B. bassiana entre insetos inoculados e sadios devido ao aumento da prevalência natural preexistente que era de $0,3 \%$ de insetos doentes.

Palavras-chave: Beauveria bassiana, Cosmopolites sordidus, epizootia
\end{abstract}

\begin{abstract}
The aim of this study was to assess the transmission of the entomopathogenic fungus Beauveria bassiana among adults of banana weevil (Cosmopolites sordidus) in the field. C. sordidus healthy adults were marked and released on the basis of banana plants. Two days later insects marked and inoculated with the entomopathogenic fungus were released in the same area. Pseudostem traps were placed at 7, 14, 21 and 28 days for recover of released insects and to evaluate the mortality. It was observed that $3.7 \%$ of the non inoculated insects died due to pathogen infection caracterizing $B$. bassiana transmission between inoculated and healthy insects due to an increase in natural pre-existing prevalescence that was $0.3 \%$ of infected insects.
\end{abstract}

Key words: Beauveria bassiana, Cosmopolites sordidus, epizooty

\footnotetext{
${ }^{1}$ Eng $^{\text {o Agro }}$, M.Sc em Fitossanidade, Servicio Agrícola y Ganadero (SAG), Bulnes 140, Santiago, Chile. E-mail: lema.ernesto@ gmail.com

${ }^{2}$ Eng $^{\mathrm{o}} \mathrm{Agr}^{\mathrm{o}}$, Prof. Dr. do Dept ${ }^{\mathrm{o}}$ de Agronomia, Universidade Estadual de Londrina, UEL, Londrina, PR. Bolsista PQ/CNPq. E-mail: pedroneves@uel.br

${ }^{3}$ Eng $^{\mathbf{0}}$ Agr $^{\mathbf{o}}$, Pesquisador Dr. da Embrapa Mandioca e Fruticultura, Cruz das Almas, BA. E-mail: fancelli@cnpmf.embrapa.br

* Autor para correspondência
} 
A banana é a fruta mais produzida no mundo e o quarto alimento mais consumido, sendo o Brasil o quarto maior produtor com uma superfície estimada de 515.000 ha (FAO, 2007). A principal praga desta cultura é Cosmopolites sordidus (Germar) (Coleoptera: Dryophthoridae), conhecida vulgarmente como broca-do-rizoma ou molequeda-bananeira e encontra-se distribuída nas regiões tropicais e subtropicais do mundo (ALVES et al., 2003).

C. sordidus possui hábitos crípticas que fazem desta praga um inseto de difícil controle com métodos tradicionais. Entretanto, diferentes trabalhos têm se realizados visando o controle com Beauveria bassiana (Bals.) Vuill. (JORDÃO et al., 1999; GODONOU et al., 2000; NANKINGA; MOORE, 2000; ALMEIDA et al., 2009). Nas lavouras comerciais, as taxas de infecção natural do inseto por $B$. bassiana tendem a ser muito baixas (GOLD; PEÑA; KARAMURA, 2001; PRESTES et al., 2006; TINZAARA et al., 2007a), levando à necessidade de desenvolvimento de uma estratégia inundativa ou inoculativa para que ocorra uma epizootia (ALVES; LECUONA, 1998).

Entre os fatores que contribuem para iniciar e desenvolver epizootia, podemos citar uma eficiente forma de transmissão do fungo (TANADA; KAYA, 1993), a qual pode ser conseguida com um método eficaz de liberação do fungo no campo, como por exemplo, o uso de armadilhas de feromônio de agregação de $C$. sordidus (TINZAARA et al., 2007b). Entretanto, embora ocorra um aumento no número de insetos inoculados nas armadilhas, é importante que os indivíduos possam dispersar-se depois de inoculados dispersando o inóculo.

Assim, o objetivo deste estudo foi avaliar a capacidade de transmissão de Beauveria bassiana entre insetos adultos em condições de campo.

Obtenção e Manutenção de $C$. sordidus. Insetos adultos de $C$. sordidus foram coletados mediante armadilhas de pseudocaule de bananeira mais feromônio Cosmolure (C) (DE GRAAF et al.,
2005; TINZAARA et al., 2007b), numa plantação comercial de banana cv. Grande Naine (Musa AAA, Subgrupo Cavendish) no Município de Ibiporã, Paraná, Brasil. Os insetos foram mantidos em condições de quarentena em caixas plásticas de 5,5 L com tampa de rede de polietileno e alimentados com pedaços de pseudocaule, trocados semanalmente e mantidos em câmara B.O.D. $\left(23 \pm 1{ }^{\circ} \mathrm{C}\right.$ e 24 horas escotofase).

Marcação e inoculação dos insetos. Todos os insetos foram separados por sexo (LONGORIA, 1968) e marcados com pequenos riscos feitos com agulha entomológica no pronoto (número de tratamento) e élitro (número de repetição) do lado esquerdo nas fêmeas ou direito nos machos. Segundo Rukazambuga (1996) citado por Nankinga e Moore (2000), este tipo de marcação não afeta a mobilidade nem a mortalidade dos insetos. Em todos os tratamentos, $70 \%$ dos insetos foram fêmeas e 30\% machos, seguindo a mesma razão sexual obtida nas capturas nos dois meses prévios ao ensaio. Logo após a marcação, os insetos foram inoculados mediante imersão por 90 segundos numa suspensão de $1 \times 10^{9}$ conídios/mL, preparada com água destilada estéril, Tween 20 a 0,005\% (v/v) e com 95\% de viabilidade (isolado CG1024) de $B$. bassiana, selecionado em bioensaios prévios como o mais virulento a $C$. sordidus. Para assegurar a infecção, antes de serem liberados no campo os insetos foram colocados para secagem durante 48 horas em placa de Petri de $9 \mathrm{~cm}$ esterilizada, em câmara B.O.D. ( $25 \pm 1{ }^{\circ} \mathrm{C}$ e 24 horas de escotofase). Uma amostra de 10 insetos tratados foi deixada em copo plástico $(150 \mathrm{ml})$ com tampa perfurada e pedaços de pseudocaule fresco para confirmação da porcentagem de mortalidade pelo patógeno.

Liberação dos insetos. Informação prévia da população de adultos de $C$. sordidus e infecção natural com $B$. bassiana foi obtida através do monitoramento da população no talhão. Em cada uma das nove touceiras da parcela experimental foram liberados seis insetos sadios (três machos e três fêmeas), previamente marcados no élitro 
esquerdo (fêmea) ou direito (macho), com um, dois, três ou quatro riscos dependendo o tratamento onde foram liberados. Dois dias após, foram liberados só na touceira central de cada parcela os tratamentos correspondentes a 10, 20 ou 40 insetos marcados e inoculados com o isolado CG1024 de B. bassiana na concentração de $1 \times 10^{9}$ conídios $/ \mathrm{mL}$, suspensão preparada do mesmo modo descrito acima, e 20 insetos sadios como testemunha. Tanto os insetos sadios como os inoculados foram liberados durante o horário da tarde depois das 17:00 h. No total do ensaio foram marcados e liberados 210 insetos inoculados com o fungo e 708 insetos sadios.

Captura dos insetos e avaliação dos tratamentos. Após sete dias da liberação dos insetos inoculados foi instalada uma armadilha de pseudocaule tipo telha em cada touceira (LINS et al., 2008). Posteriormente, aos 7, 14, 21 e 28 dias, após a liberação, avaliou-se em cada armadilha o número de insetos capturados. A cada avaliação foram renovadas todas as armadilhas. Os insetos coletados foram transferidos ao laboratório e identificados, segundo sexo, tratamento, repetição, quando marcados, ou da população do campo sem marcação, e deixados em quarentena por vinte e cinco dias em copos plásticos de $0,5 \mathrm{~L}$ mais pedaços de pseudocaule em câmara B.O.D. $\left(25 \pm 1^{\circ} \mathrm{C}\right.$ e 24 horas de escotofase). As avaliações de mortalidade foram diárias, sendo que os insetos mortos foram lavados com uma solução de hipoclorito de sódio
(1\%) e água destilada por $30 \mathrm{seg}$. e colocados individualmente em câmara úmida para a confirmação de mortalidade pelo fungo.

Desenho experimental. O estudo foi efetuado em um talhão de $3.000 \mathrm{~m}^{2}$ com plantas de nove anos de idade no espaçamento de 2 x 2,5 m. Cada unidade experimental foi formada por nove touceiras. $\mathrm{O}$ desenho experimental teve delineamento em blocos casualizados com quatro tratamentos (número de insetos inoculados liberados) e três repetições. Os dados de mortalidade total e confirmada dos insetos sadios marcados, assim como dos insetos naturais do campo, foram submetidos a teste de homogeneidade de variância e normalidade de resíduos. Devido à não adequação dos dados ao modelo, os dados foram submetidos ao teste não paramétrico com K amostras relacionadas, Teste de Friedman, mediante o programa estatístico BioEstat 5.0.

Os dados climáticos de temperatura máxima, mínima, média, umidade relativa do ar e precipitação do período do ensaio, foram fornecidos pela Estação Meteorológica do IAPAR (Instituto Agronômico de Paraná), localizada nas proximidades da área experimental, em Ibiporã, PR.

Do total de insetos inoculados (210) e sadios (708) liberados nos distintos tratamentos, quatro $(1,9 \%)$ e oitenta e cinco $(12,0 \%)$ foram capturados, respectivamente. Mil e dezoito insetos capturados eram não marcados (Tabela 1).

Tabela 1. Total de insetos liberados inoculados e sadios, e insetos não marcados capturados com armadilhas tipo telha (pseudocaule) e mantidos em quarentena no laboratório.

\begin{tabular}{lcccc}
\hline \multirow{2}{*}{ Capturados } & \multicolumn{4}{c}{ Insetos observados após a quarentena $^{1}$} \\
\cline { 2 - 5 } & Vivos & Mortos sem fungo & Mortos com B. bassiana & Infecção (\%) \\
\hline Liberados inoculados & 1 & 1 & 2 & 50 \\
Liberados sadios & 78 & 3 & 4 & 4,7 \\
Não marcados & 878 & 102 & 38 & 3,7 \\
\hline
\end{tabular}

${ }^{1}$ valores correspondem à soma de todos os tratamentos e repetições das quatro avaliações efetuadas.

Fonte: Elaboração dos autores. 
Durante o período de avaliação foi registrada temperatura média de $22^{\circ} \mathrm{C}$, umidade relativa de $74,1 \%$ e $441,6 \mathrm{~mm}$ de precipitação. Estes fatores não foram, provavelmente, deletérios ao fungo, pois estavam na considerada faixa ideal para o desenvolvimento de $B$. bassiana, que são temperaturas entre 22 a $26{ }^{\circ} \mathrm{C}$ e $70-100 \%$ UR (ALVES; LECUONA, 1998).

Deve-se considerar que o isolado CG1024 utilizado neste ensaio foi coletado na Bahia, possivelmente adaptado a condições climáticas distintas das do Paraná o que pode ter afetado a efetividade do fungo em condições de campo. No presente trabalho observou-se que a porcentagem de infecção dos insetos liberados sadios $(4,7 \%)$ e dos não marcados $(3,7 \%)$ (Tabela 1$)$ foi maior do que a porcentagem da infecção natural média $(0,3 \%)$ avaliada nos últimos seis meses (março-agosto) antes do inicio do estudo. Valores similares foram obtidos por Tinzaara et al. (2007a) em um ensaio de transmissão horizontal de $B$. bassiana sobre $C$. sordidus em condições de campo. Estes autores indicam que 4 a 7\% dos insetos sadios capturados morreram devido à infecção com $B$. bassiana depois da incubação em laboratório.

Estes valores de incidência da doença causaram um aumento da prevalência, o que poderia evidenciar uma potencial transmissão no campo entre os insetos mortos pelo fungo e os sadios. Não obstante, estes valores ainda são baixos e não representam uma eficiente taxa de transmissão para alcançarem uma epizootia, as quais estão caracterizadas por um súbito aumento da prevalência e incidência devido ao desequilíbrio num curto período de tempo (FUXA;TANADA, 1987).

Só foi observada mortalidade por B. bassiana nos tratamentos T2 (liberação de 20 insetos inoculados) e T4 (liberação 20 insetos sadios), mas devido à alta variação dos resultados a comparação de médias entre todos os tratamentos não foi estatisticamente diferente (Tabela 2).

Tabela 2. Porcentagem de infecção média do fungo B. bassiana sobre adultos de C. sordidus capturados com armadilhas telha. Ibiporã, 2009.

\begin{tabular}{lc}
\hline \multicolumn{1}{c}{ Tratamentos $^{(1)}$} & Infecção com B. bassiana $(\%){ }^{(\mathrm{ns})}$ \\
\hline T1 (10 insetos inoculados) & 0 \\
T2 (20 insetos inoculados) & 5,6 \\
T3 (40 insetos inoculados) & 0 \\
T4 (20 insetos sadios) & 12,5 \\
\hline
\end{tabular}

${ }^{1}$ Adultos de $C$. sordidus inoculados em laboratório mediante imersão em suspensão de 1 x $10^{9}$ conídios $/ \mathrm{ml}$ de isolado de $B$. bassiana CG1024, e liberados posteriormente no campo.

ns Não significativa pelo teste de comparação de médias Friedman a 5\%.

Fonte: Elaboração dos autores.

A maior porcentagem de mortalidade pelo fungo foi observada no T4 (12,5\%), correspondente a liberação de adultos sadios, os quais sempre foram recapturados na mesma área de liberação, o que permite supor que a infecção foi causada pela transmissão do fungo a partir dos insetos inoculados e não pela movimentação dos insetos entre tratamentos/parcelas. Esta transmissão também pode ter acontecido pela inoculação dos conídios levados pela chuva, uma vez que os insetos inoculados apresentam mobilidade diminuída (TINZAARA et al., 2007a).

Observou-se uma provável transmissão de B. bassiana entre insetos inoculados e sadios, com aumento da prevalência de 0,3 (anterior ao experimento)para 3,7 e 4,7\% após a liberação do fungo. 


\section{Agradecimentos}

Ao CNPq pela concessão de bolsa de mestrado. À Biocontrol pelo fornecimento do feromônio. E à EMBRAPA pelo financiamento do projeto.

\section{Referências}

ALMEIDA, A. M. B.; BATISTA FILHO, A.; TAVARES, F. M.; LEITE, L. G. Seleção de isolados de Beauveria bassiana para o controle de Cosmopolites sordidus (Germar, 1824) (Coleoptera: Curculionidae). Arquivos do Instituto Biológico, São Paulo, v. 76, n. 3, p. 489-493, jul./set. 2009.

ALVES, S. B.; LECUONA, R. E. Epizootiologia aplicada ao controle microbiano de insetos. In: ALVES, S. B. (Org.). Controle microbiano de insetos. 2. ed. Piracicaba: FEALQ, 1998. cap. 5, p. 97-170.

ALVES, S. B.; PEREIRA, R. M.; LOPES, R. B.; TAMAI, M. A. Use of entomopathogenic fungi in Latin America. In: UPADHYAY, R. K. (Org.). Advances in microbial control of insect pest.USA: Kluwer Academic/Plenum Publishers, 2003. p. 193-211.

DE GRAAF, J.; GOVENDER, P.; SCHOEMAN, A. S.; VILJOEN, A. Efficacy of pseudostem and pheromone seasonal trapping of the banana weevil Cosmopolites sordidus in South Africa. International Journal of Pest Management, Inglaterra, v. 51, n. 3, p. 209-218, jul. 2005.

FAO. Faostat. 2007. Disponível em:<http://faostat.fao. org >. Acesso em: 9 nov. 2009.

FUXA, J. R.; TANADA, Y. Epizootiology of insect diseases. New York: Wiley Interscience Publ., 1987.

GODONOU, I.; GREEN, K. R.; ODURO, K. A.; LOMER, C. J.; AFREH-NUAMAH, K. Field evaluation of selected formulations of Beauveria bassiana for the management of the banana weevil (Cosmopolites sordidus) on plantain (Musa spp., AAB group). Biocontrol Science and Technology, Inglaterra, v. 10, n. 6, p. 779-788, dez. 2000.

GOLD, C. S.; PEÑA, J. E.; KARAMURA, E. B. Biology and integrated pest management for the banana weevil Cosmopolites sordidus (Germar) (Coleoptera: Curculionidae). Integrated Pest Management Reviews, Holanda, v. 6, n. 2, p. 79-155, jun. 2001.
JORDÃO, A. L.; BATISTA FILHO, A.; LEITE, L. G.; BERIAM, L. O. S.; ALMEIDA, J. E. M. Caracterização e eficiência de isolados de Beauveria bassiana (Bals.) Vuill. no controle de Cosmopolites sordidus. Arquivos do Instituto Biológico, São Paulo, v. 66, n. 2, p. 107-111, jul./dez. 1999.

LINS, R. D.; DANTAS, A. C. V. L.; FANCELLI, M.; CARVALHO, C. A. L.; LEITE, J. B. V. Infestação da broca-do-rizoma em variedades e híbridos de bananeira em una, Bahia. Magistra, Cruz das Almas, v. 20, n. 1, p. 105-108, jan./mar. 2008.

LONGORIA, A. G. G. Diferencias sexuales en la morfologia externa de Cosmopolites sordidus Germar (Coleoptera, Curculionidae). Ciencias Biologicas, La Habana-Cuba, n. 1, p. 01-11, maio 1968.

NANKINGA, C. M.; MOORE, D. Reduction of banana weevil populations using different formulations of the entomopathogenic fungus Beauveria bassiana. Biocontrol Science and Technology, Inglaterra, v. 10, n. 5, p. 645-657, out. 2000.

PRESTES, T. M. V.; ZANINI, A.; ALVES, L. F. A.; BATISTA FILHO, A.; RODHE, C. Aspectos ecológicos da população de Cosmopolites sordidus, (Germar) (Coleoptera: Curculionidae) em São Miguel do Iguaçu, PR. Semina: Ciências Agrárias, Londrina, v. 27, n. 3, p. 333-350, jul./set. 2006.

TANADA, Y.; KAYA, H. Insect pathology. New York: Academic Press, 1993.

TINZAARA, W.; GOLD, C. S.; DICKE, M.; VAN HUIS, A.; NANKINGA, C. M.; KAGEZI, G. H.; RAGAMA, P. E. The use of aggregation pheromone to enhance dissemination of Beauveria bassiana for the control of the banana weevil in Uganda. Biocontrol Science and Technology, Inglaterra, v. 17, n. 2, p. 111-124, mar. $2007 \mathrm{a}$.

TINZAARA, W.; GOLD, C. S.; DICKE, M.; VAN HUIS, A.; RAGAMA, P. E. Host plant odours enhance the responses of adult banana weevil to the synthetic aggregation pheromone Cosmolure+. International Journal of Pest Management, Inglaterra, v. 53, n. 2, p. 127-137, abr./jun. 2007b. 
